\title{
Review Article \\ Parametric Conversion in Micrometer and Submicrometer Structured Ferroelectric Crystals by Surface Poling
}

\author{
Alessandro C. Busacca, ${ }^{1}$ Salvatore Stivala, ${ }^{1}$ Luciano Curcio, ${ }^{1}$ and Gaetano Assanto ${ }^{2}$ \\ ${ }^{1}$ DIEET, University of Palermo, Viale delle Scienze, Building no. 9, 90128 Palermo, Italy \\ ${ }^{2}$ Nonlinear Optics and OptoElectronics Laboratory (NooEL), University Roma Tre, Via della Vasca Navale 84, 00146 Rome, Italy
}

Correspondence should be addressed to Gaetano Assanto, assanto@uniroma3.it

Received 27 July 2011; Accepted 26 September 2011

Academic Editor: Arnaud Mussot

Copyright (C) 2012 Alessandro C. Busacca et al. This is an open access article distributed under the Creative Commons Attribution License, which permits unrestricted use, distribution, and reproduction in any medium, provided the original work is properly cited.

\begin{abstract}
We report on recent technological improvements concerning nonlinear patterning of lithium niobate and lithium tantalate in the micrometer and submicrometer scales using surface periodic poling for ferroelectric domain inversion. The fabricated samples were employed for frequency doubling via quasiphase-matching both in bulk and guided wave geometries, including forward and backward configurations and wavelength conversion in bands C and L. We also investigated short-period quasiperiodic samples with randomly distributed mark-to-space ratios.
\end{abstract}

\section{Introduction}

Optical frequency conversion in parametric media is one of the most important applications in nonlinear optics, as it allows generating coherent light in regions of the spectrum where laser emission is not available. Moreover, through a careful engineering of the phase mismatch and excitation(s), several signal processing schemes can benefit of parametric nonlinearities via cascading [1-7]. Since the first experiments on second-harmonic generation (SHG) [810], a great effort has been devoted towards developing configurations with the highest conversion efficiencies [11, $12]$. Among them, quasi-phase matching (QPM) is one of the most useful and versatile techniques for efficient frequency conversion, allowing continuous growth of the generated wave along the propagation length despite the local phase velocity mismatch (hence, lack of momentum conservation) between the interacting waves $[13,14]$. This can be achieved thanks to a correction of their relative phases by means of a structural periodicity built in the nonlinear medium; more precisely, a periodic sign change of the quadratic coefficient $\chi^{(2)}$ as it can be achieved in noncentrosymmetric crystals, for example, lithium niobate (LN) and lithium tantalate (LT), via periodic poling (PP).
Several techniques have been developed for PP, including domain inversion during crystal growth [15], spontaneous Curie temperature poling using heat [16], chemical reactions or substitution of impurities $[17,18]$, electron beam [19-22], and electric field assistance [23-25]. In recent years, surface periodic poling (SPP) was introduced as a PP approach for the fine tuning of the mark-to-space ratios in shortperiod QPM, aiming at the realization of smaller and smaller domain lengths for sum-frequency generation at shorter wavelengths, as well as backward or counterpropagating wave mixing [26-36]. Surface periodic poling is based on the overpoling of a ferroelectric substrate and provides periodic domain inversion with shallow domain depths as compared to the thickness of the substrate [30]. Short domains are also useful for broadband SHG: once the nonlinear (QPM) grating is fabricated, irregularities of the periodic structure lead to a random distribution of the mark-to-space ratio (MTSR) which has a relevant role when the desired pattern has small features (Figure 1(a)). The random modulation of the nonlinear coefficient allows phase matching between the fundamental (FF) and the SH beam thanks to the presence of several reciprocal lattice vectors (see Figure 1(b)), and, even far away from the QPM-SHG resonance, the harmonic signal remains remarkably large as compared to that generated 


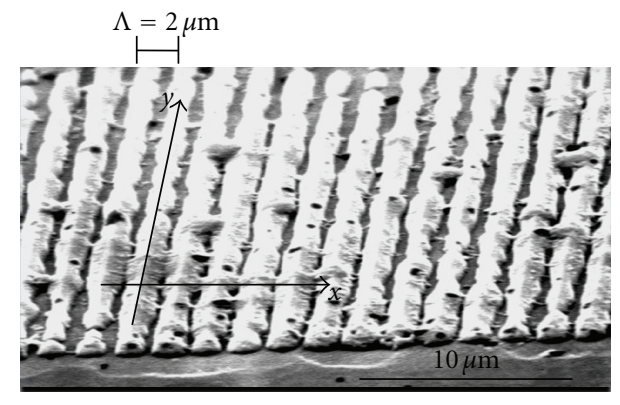

(a)

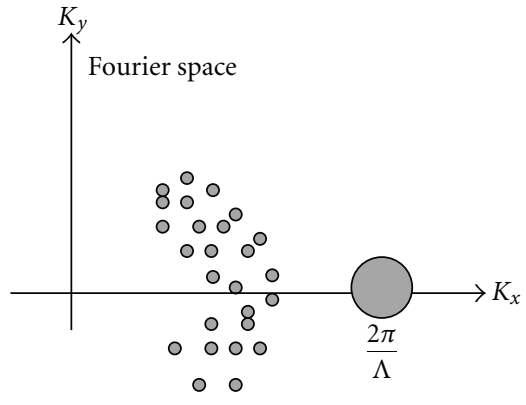

(b)

FIGURE 1: (a) Micrograph of an SPP-LT sample after chemical etching; a nonuniform mark-to-space ratio is visible in the poled area with $2-\mu \mathrm{m}$ period. (b) Fourier spectrum of the nonlinear distribution shown in (a).

in unpoled regions. While the $\mathrm{SH}$ output profile in space becomes strongly dependent on the wavelength (in the absence of effective self-focusing via cascading [37-40]), the randomized quasiphase matching (rQPM) process is quite broadband [41-44].

In this paper, we review some of the most recent technological improvements on QPM patterning of LN and LT in the micrometer and submicrometer scale. The fabricated samples were tested and used for parametric frequency doubling and difference frequency generation (DFG) via bulk and guided wave parametric interactions, including forward and backward configurations. We also characterized the rQPM interaction for SHG.

\section{Sample Fabrication}

In order to achieve QPM and efficient parametric interactions for frequency conversion, domain inversion at the required period needs to be implemented. In some applications, such as first-order forward-SHG in LN and LT from fundamental wavelengths in the $\mathrm{C}$ band of optical communications, typical periods amount to about $20 \mu \mathrm{m}$ [4547]. For other scopes, such as UV generation or backwardSHG, shorter periods are required: UV generation via frequency doubling can be achieved by employing periods of a few microns [48], while backward-SHG (at low order QPM) needs submicron periods [49-53]. Adopting the SPP approach, we were able to fabricate ferroelectric samples with periods in the micron and submicron range $[30,32,54,55]$.

The samples were prepared from standard optical grade wafer substrates of congruent LN or LT of thickness $500 \mu \mathrm{m}$ $[54,56]$. For SPP we used high-voltage pulses applied across the thickness in order to achieve overpoling. We spin coated the $-Z$ face of the crystal slab with a photoresist film (Shipley S1813) and defined the desired periodic pattern by standard photolithography. After development, the pattern was soft baked overnight at $90^{\circ} \mathrm{C}$ and hard baked at $130^{\circ} \mathrm{C}$ for 3 hours. The temperature was raised gradually in order to avoid problems due to pyroelectric effects, the formation of poling dots, and the insurgence of mechanical stress in the bulk. The baked photolithographic mask served as the insulating layer during high-voltage poling for producing domain inversion, although SPP was also occasionally carried out with the aid of photolithographically defined silica masks, the latter improving the duty cycle control with 50:50 MTSR [32].

The samples were then placed between two electrodes covered with a thin gel electrolyte to ensure proper electric contact. Hence, the LT (or LN) interfaces were connected to a high-voltage waveform generator (Agilent $3220 \mathrm{~A}$ ) after amplification (Trek 662). A digital oscilloscope helped monitoring the waveforms of both the poling voltage and the displacement current.

To exceed the coercive field in the ferroelectric crystals and obtain surface periodic inversion, we applied $1.3 \mathrm{kV}$ pulses over a $10 \mathrm{kV}$ bias for an appropriate time interval, in order to fulfill the overpoling condition:

$$
Q>2 A P_{s},
$$

with $Q$ the flowing charge, $A$ the poled area, and $P_{s}$ the spontaneous polarization of the material. With this approach, even without a precise control of the flowing charge, one can allow the domain walls to completely merge on the $+Z$ face of the crystal but not underneath the insulated portions of the $-Z$ face, where the original ferroelectric orientation gets preserved in a periodic fashion (see Figure 2). We could evaluate the domain uniformity, depth, and MTSR by etching the poled samples in diluted hydrofluoric acid (HF, 50\%) and investigating the periodic grating by a scanning electron microscope (SEM).

Submicron gratings were written on a photoresist mask by means of an interferometric pattern obtained with the $441.6 \mathrm{~nm}$ light emitted by a He-Cd laser. The samples, coated with a $400 \mathrm{~nm}$ thick spun photoresist (Shipley S1805), were arranged in the Lloyd configuration with a mirror orthogonal to the surface (see Figure 3). The $6 \mathrm{~mW} \mathrm{He-Cd}$ beam was expanded and collimated to the sample-mirror system, one half being reflected and forming interference fringes with period $\Lambda=\lambda /[2 \sin (\theta)]$ with the other half, being $\theta$, the angle between the beam and the normal to the sample, as set by a rotation stage. The exposure time was about $15 \mathrm{~s}$. Since LN and LT are transparent in the near UV, we also covered the sample back face with a matching index liquid in order to minimize the detrimental effects of multiple reflections on the fringe visibility. After exposure, 


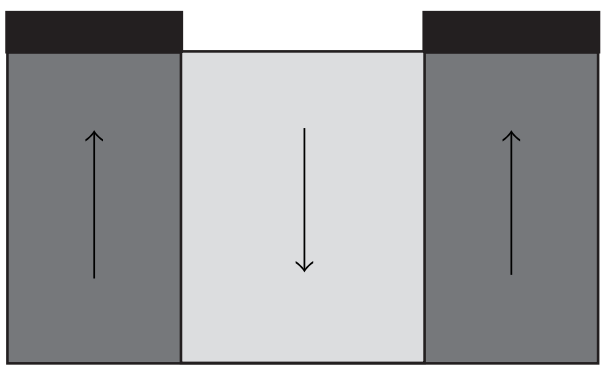

(a)

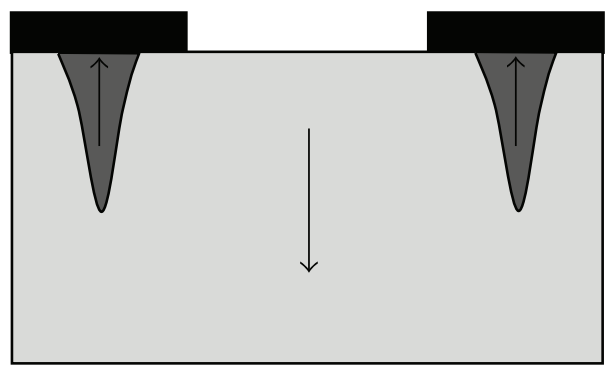

(b)

FIGURE 2: (a) Bulk periodic poling and (b) surface periodic poling.

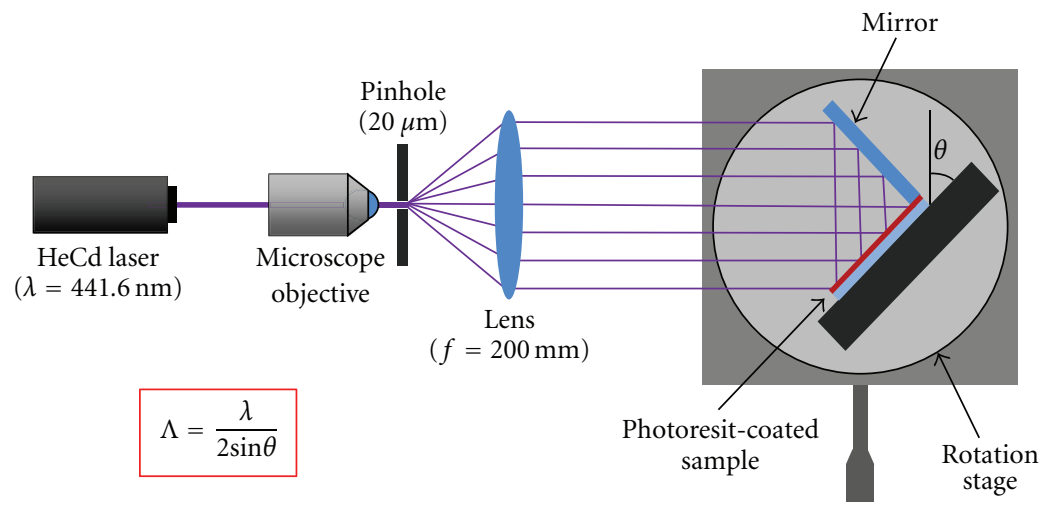

FIGURE 3: Lloyd mirror configuration for interferometric writing of submicrometric gratings.

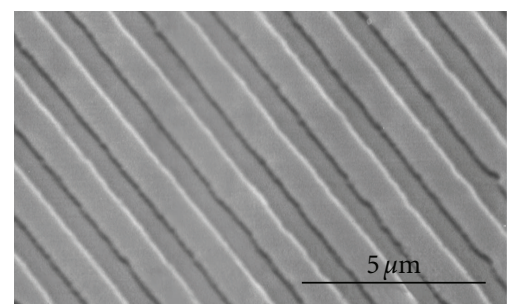

(a)

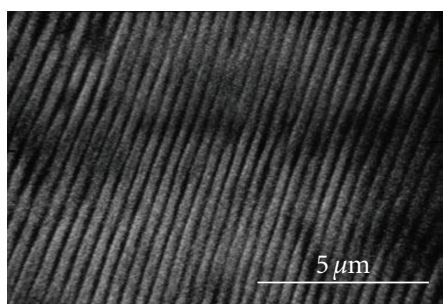

(b)

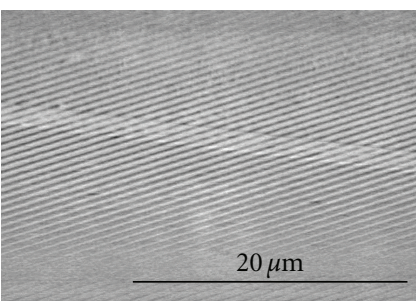

(c)

FIgURE 4: (a) SPP-LT with period $1.5 \mu \mathrm{m}$; (b) SPP-LN with period $400 \mathrm{~nm}$; (c) PE channel waveguide fabricated on SPP-LN.

the photoresist development was checked by measuring the grating diffraction efficiency under He-Ne laser illumination. We were able to produce good quality $400 \mathrm{~nm}$ period gratings that were employed as insulating masks during SPP [56].

Table 1 summarizes the technological details for various samples. Figure 4 displays the scanning electron microphotographs of typical periodic QPM gratings.

In order to enhance the parametric conversion efficiency, we often resorted to fabricating optical waveguides; this ensured tightly confined interacting waves over the whole propagation length and, therefore, higher and nearly constant intensities with respect to bulk, where diffraction occurs.

Among the available techniques for waveguide fabrication, we chose proton exchange (PE) in the $\alpha$-phase [57], as it preserves the nonlinear properties of the crystal and is compatible with the electric field poling of the ferroelectric domains in both LN and LT [58-60]. The poled substrates were initially coated with a $\mathrm{SiO}_{2}$ layer; channel openings, typically from 1 to $7 \mu \mathrm{m}$ in width, were defined by standard photolithography and wet etching in HF (Figure 5(a)). Proton exchange was then carried out by dipping the LN/LT sample in a solution of benzoic acid (BA) and 3-3.6\% lithium benzoate (LB) using the sealed-ampoule method [60], as sketched in Figure 5(b). This yielded an extraordinary refractive index increase $\left(\Delta n_{e}\right)$ and low proton concentration ( $\alpha$-phase) channel waveguides supporting TM-polarized modes. We verified the compatibility between SPP and PE by chemically etching the samples and using scanning electron microscopy as well as by performing nonlinear measurements in guided-wave configurations [46, 48, 61]. Figure 4(c) shows the optical micrograph of a typical channel on a PP substrate after HF etching. 
TABLE 1

\begin{tabular}{lcccc}
\hline Substrate & QPM period $(\Lambda)$ & Photoresist thickness & Pulse duration & Reference \\
\hline LT & $20.8 \mu \mathrm{m}$ & $1.7 \mu \mathrm{m}$ & $500 \mu \mathrm{s}$ & $400 \mu \mathrm{s}$ \\
LN & $3.2 \mu \mathrm{m}$ & $2.0 \mu \mathrm{m}$ & $35]$ & $300 \mu \mathrm{s}$ \\
LT & $2.0 \mu \mathrm{m}$ & $1.3 \mu \mathrm{m}$ & $300 \mu \mathrm{s}$ & {$[53]$} \\
LT & $1.5 \mu \mathrm{m}$ & $1.3 \mu \mathrm{m}$ & $30,41]$ \\
\hline
\end{tabular}
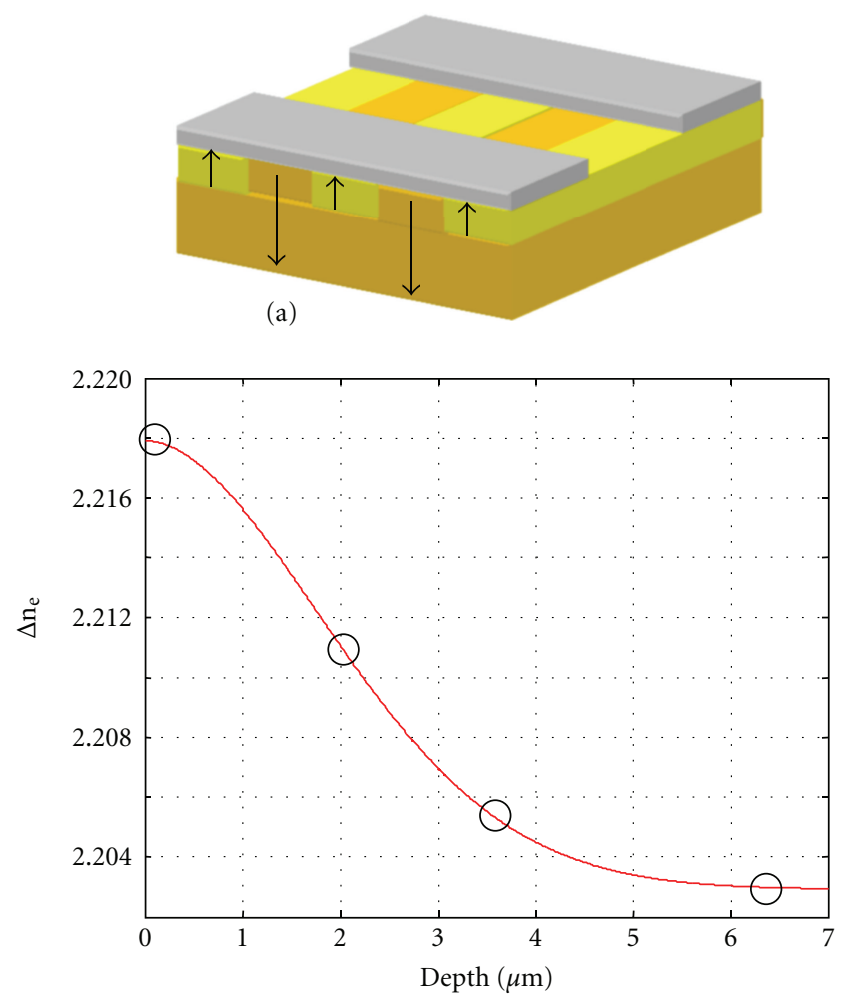

(c)

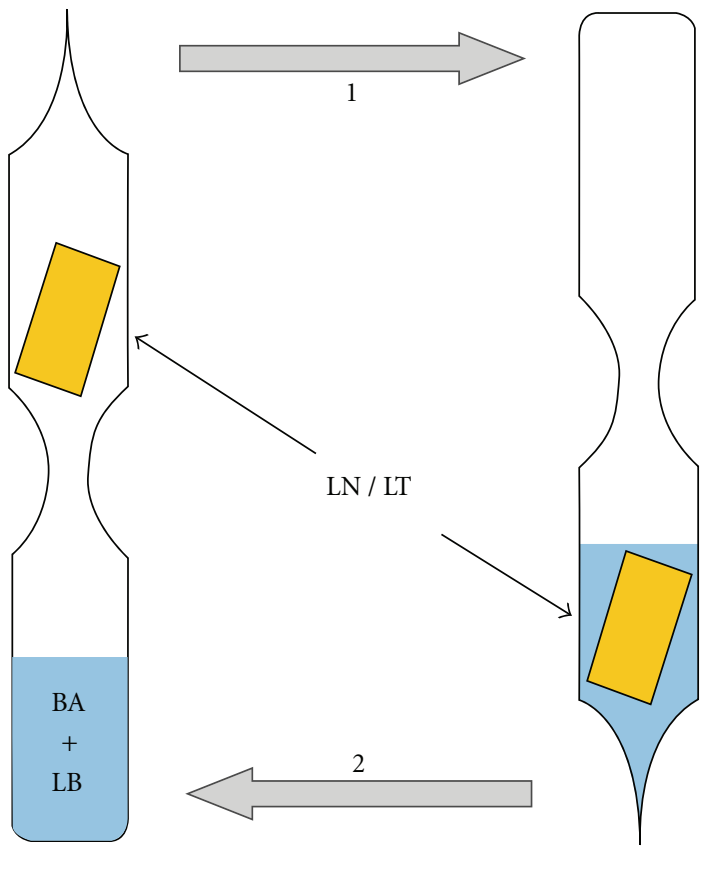

(b)

Figure 5: (a) Channel waveguide in a PPLN/PPLT sample. (b) Sealed ampoule technique. (c) Extraordinary index profile calculated by inverse WKB from distributed coupling data; dots are measured effective indices at $632.8 \mathrm{~nm}$, and the solid line is a WKB fit.

We also employed planar waveguides formed on the $+Z$ face of the samples for distributed prism coupling and the evaluation of the extraordinary index profile versus depth $z$ using the standard WKB method [62]. Figure 5(c) shows an example of such a profile in a PE-SPPLN waveguide fabricated by using a solution of $\mathrm{BA}+3 \% \mathrm{LB}$ and proton exchange at $300^{\circ} \mathrm{C}$ for 96 hours.

\section{Parametric Characterization}

After fabrication, our samples were nonlinearly characterized and tested: the inversion of the quadratic coefficient with different periods allowed us to achieve efficient parametric frequency doubling at the corresponding QPM resonant wavelength in each configuration (forward or backward) or to obtain broadband SHG via randomized QPM. Hereby, we report on typical experimental results obtained either in bulk or in channels from three different samples with micronscale domain inversion.
The first sample was a PPLN bulk with a one-dimensional grating of period $3.2 \mu \mathrm{m}$ over a length of $3 \mathrm{~mm}$. For the nonlinear measurements, we used an Argon-ion pumped CW Ti: Sapphire laser, with a $40 \mathrm{GHz}$ linewidth and wavelength tunable between 860 and $1000 \mathrm{~nm}$; with an $f=11$ $\mathrm{mm}$ lens, the TEM $\mathrm{T}_{00}$ beam was gently focused to a waist of $30 \mu \mathrm{m}$ in the middle of the poled area, in a crystal kept at a constant temperature of $195^{\circ} \mathrm{C}$ to reduce or prevent the risk of photorefractive damage. The FF beam was mechanically chopped at $133 \mathrm{~Hz}$, and the generated $\mathrm{SH}$ signal was collected by a photomultiplier tube for synchronous detection; the residual pump was eliminated with the aid of a dichroic mirror and selective bandpass filters. Initially, we studied the $\mathrm{SH}$ generated forward via first-order QPM by light at $\lambda_{\mathrm{FF}}=$ $862.33 \mathrm{~nm}$. We spectrally resolved the QPM SHG resonance by varying either the FF wavelength (Figure 6(a)) or the temperature (Figure 6(b)) while keeping the other parameters constant. We then verified the quadratic growth of the $\mathrm{SH}$ versus FF excitation (Figure 6(c)). BSHG measurements were also performed on the same sample, and Figure 7(a) 


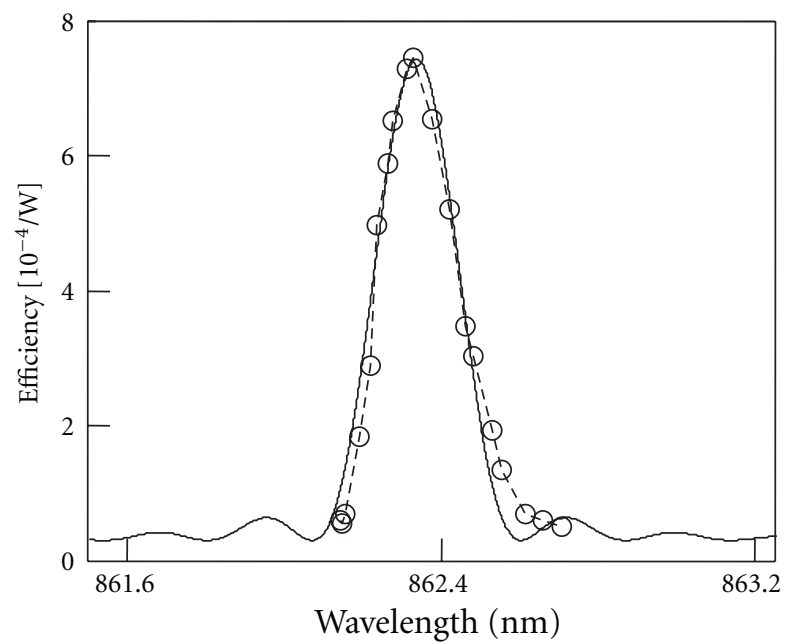

(a)

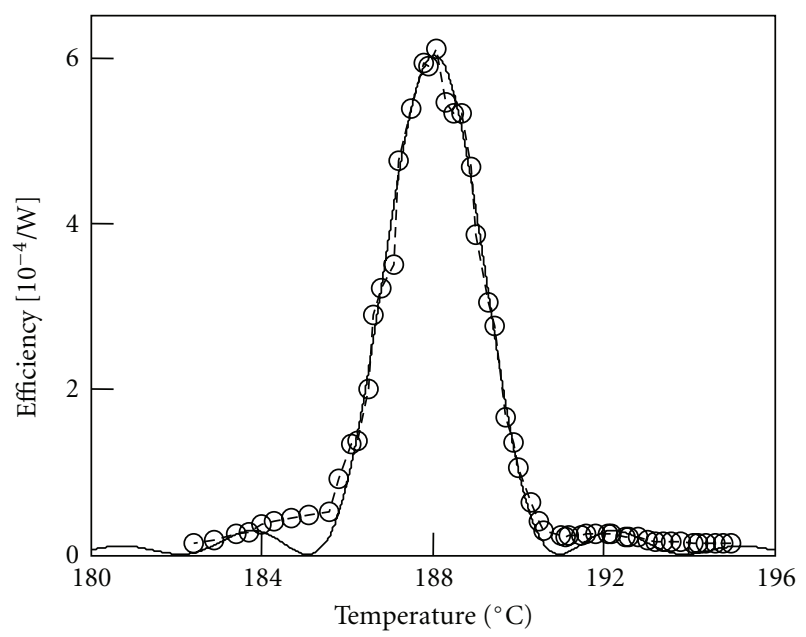

(b)

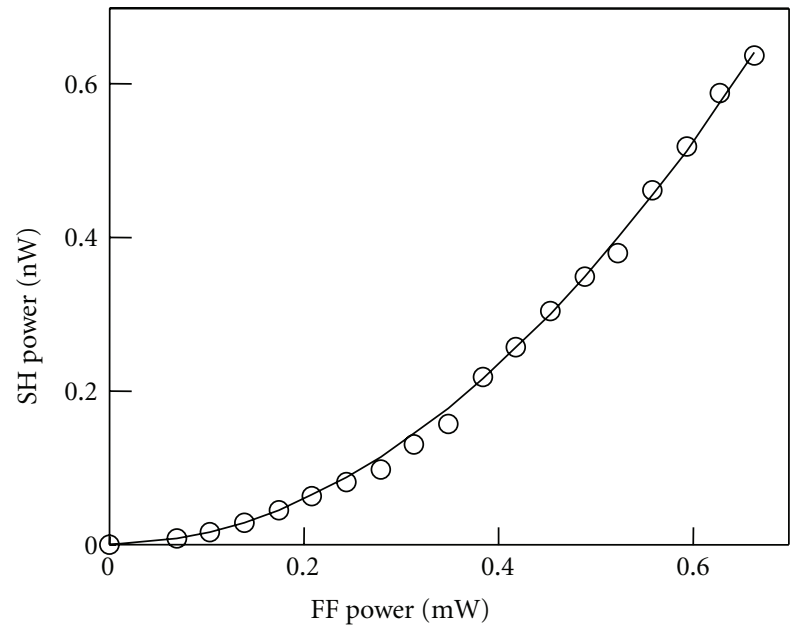

(c)

FIGURE 6: Normalized SHG conversion efficiency versus (a) FF wavelength and (b) temperature for an input power of $0.7 \mathrm{~mW}$; (c) parabolic trend of the generated SH versus FF input power at the QPM resonant wavelength.

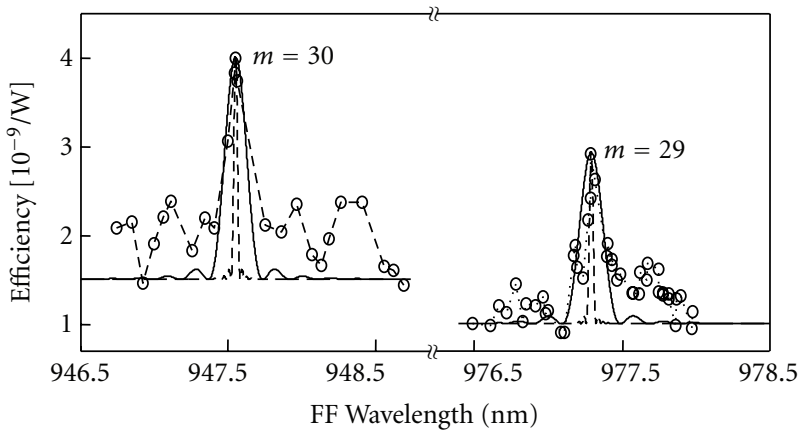

(a)

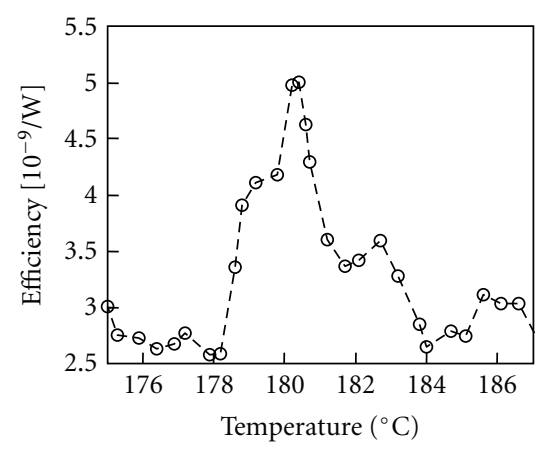

(b)

FIGURE 7: (a) Normalized BSHG conversion efficiency versus FF wavelength for the 29th and 30th QPM orders; (b) normalized conversion efficiency for the 30th BSHG order versus temperature. 
shows the normalized BSHG conversion efficiency versus input FF wavelength for the 29th and 30th grating orders of QPM-BSHG. The presence of frequency-doubled light at both odd and even resonant orders is attributed to the unbalanced duty cycle. The BSHG power at resonance grew quadratically with FF excitation; Figure 7(b) shows the normalized BSHG conversion efficiency (30th order) versus temperature, the latter permitting the fine tuning of the resonance. The 30th resonant order resulted to be the most efficient as we obtained up to $17.2 \mathrm{pW}$ of backward $\mathrm{SH}$ power by using an FF excitation of $55.12 \mathrm{~mW}$, corresponding to a maximum conversion efficiency $\eta=3.12 \cdot 10^{-8} \%$. Considering an effective length of $0.5 \mathrm{~mm}$ for the grating [53], the maximum normalized efficiency is $\eta^{\prime}=1.13$. $10^{-5} \% \mathrm{~W}^{-1} \mathrm{~cm}^{-1}$. This value is remarkably high if compared to what obtained in similar LN samples with a $3.3 \mu \mathrm{m}$ poling period. For example, in [49], a normalized efficiency of $7 \cdot 10^{-9} \% \mathrm{~W}^{-1} \mathrm{~cm}^{-1}$ was achieved by exciting the sample in the fs regime at a lower resonant order (17th). Moreover, the maximum efficiency we got is of the same order of magnitude of what reported in [50] by using a ns source to excite the 16th resonant order: $\eta=0.296 \%$ for a pump power of $33.75 \mathrm{~kW}$ and an interaction length of $4 \mathrm{~mm}$, corresponding to a normalized efficiency $\eta^{\prime}=2.19 \cdot 10^{-5} \% \mathrm{~W}^{-1} \mathrm{~cm}^{-1}$.

The second sample consisted of PE channel waveguides fabricated on a LT substrate with a $10 \mathrm{~mm}$ long $2.0 \mu \mathrm{m}$ periodic pattern for QPM. For the characterization, we used the same source described above, with the beam end-fire coupled to the channels by a $10 \mathrm{x}$ microscope objective, keeping the sample at a constant temperature of $250 \pm 0.1^{\circ} \mathrm{C}$ against photorefractive damage.

A filter at the waveguide output helped eliminating the fundamental frequency pump in the near infrared, and another filter suppressed the remaining Argon-ion light. The generated SH power in the UV was measured with a calibrated Silicon photodiode, with a mechanical chopper and a lock-in amplifier to reduce the noise level.

Figure 8 plots the generated $\mathrm{SH}$ power versus input FF wavelength in $7 \mu \mathrm{m}$ wide channels: the SHG resonance occurred between fundamental order TM modes for an input wavelength close to $730.7 \mathrm{~nm}$. These $\alpha$-phase PE SPPLT waveguides, featuring a short $2.0 \mu \mathrm{m}$ QPM period, were the first coherent integrated optics UV parametric sources at $365.4 \mathrm{~nm}$, with remarkably high conversion efficiencies exceeding $7.5 \% \mathrm{~W}^{-1} \mathrm{~cm}^{-2}$ [48]. The latter value is comparable to what reported in [63], where a normalized conversion efficiency of $8.4 \% \mathrm{~W}^{-1} \mathrm{~cm}^{-2}$ was achieved for SHG with FF in the C-band of optical communications using reverse-PE optical waveguides in PP stoichiometric LT (definitely more expensive than congruent LT). Similar results were achieved in alpha-phase PE channel waveguides with electric field SPP of congruent lithium niobate crystals: we obtained UV SHG at $390 \mathrm{~nm}$ via first-order QPM by the fabrication of periodic structures with a pitch as small as $750 \mathrm{~nm}$ [64].

On the same sample but in a bulk configuration, we also performed broadband SHG via rQPM far from the resonance. When exciting the sample with a Gaussian beam at the resonant FF wavelength, we obtained at the output a bell-shaped $\mathrm{SH}$ profile across the whole domain-inverted

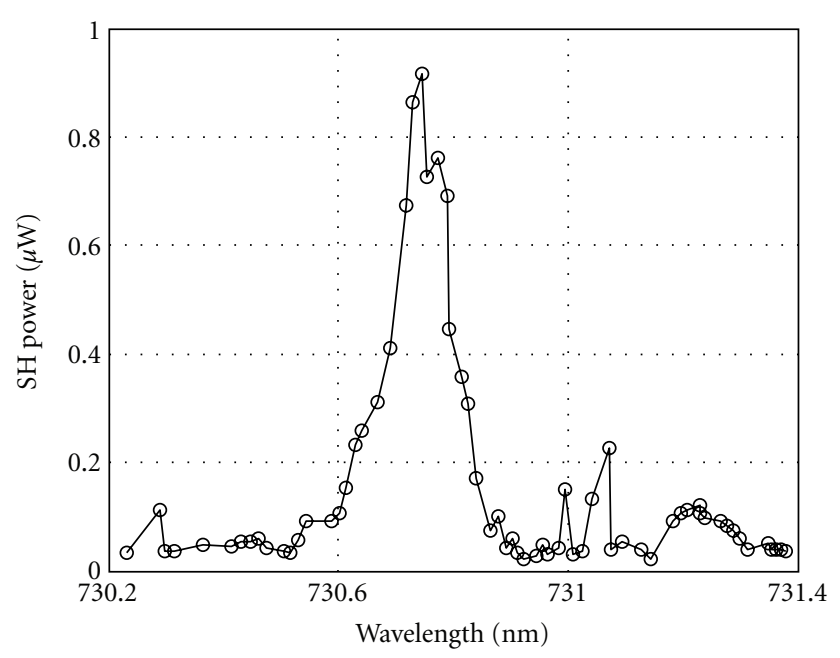

FIGURE 8: $\mathrm{SH}$ power generated in a $7 \mu \mathrm{m}$ wide channel versus FF input wavelength.

substrate. This stems from first-order QPM in bulk, due to the $2.0 \mu \mathrm{m}$ periodicity in the $\left(d_{33}\right)$ quadratic nonlinearity; however, wavelength detunings as small as $1 \mathrm{~nm}$ abruptly caused the SH level to drop down at the level of the background noise. The random-QPM contribution manifested at FF wavelengths above $900 \mathrm{~nm}$, where we could observe larger $\mathrm{SH}$ powers increasing with FF wavelength: the parabolic increase versus input FF power at $\lambda_{\mathrm{FF}}=929.66 \mathrm{~nm}$ is clearly visible in Figure 9(a). This rQPM-SHG process exhibited a conversion efficiency of about $4 \cdot 10^{-5} \% \mathrm{~W}^{-1} \mathrm{~cm}^{-1}$, about 1 order of magnitude lower than at resonance and more than one order of magnitude higher than what reported in [65], where a similar configuration was explored in $\mathrm{Sr}_{x} \mathrm{Ba}_{1-x} \mathrm{Nb}_{2} \mathrm{O}_{6}$ crystals. The near-field CCD images of the $\mathrm{SH}$ showed a random set of finger-like features, parallel to one another and to the $Z$ axis, with intensities and distributions strongly depending on location and wavelength of the input FF beam. The nonresonant trend of the SHG is characteristic of rQPM and is shown in Figure 9(b), graphing $\mathrm{SH}$ conversion efficiency versus FF wavelength [41].

Finally, we used the slab waveguide on the $+Z$ facet of the same sample for experiments on parametric beam selftrapping (via cascading) in the presence of rQPM. Since high intensities are required for this kind of experiments, in order to avoid photorefractive damage, we used a pulsed source with a low repetition rate. We employed 25 ps pulses from a $10 \mathrm{~Hz}$ parametric generator tunable in the near-IR with a linewidth $\leq 2 \mathrm{~cm}^{-1}$. The beam was filtered to the $\mathrm{TEM}_{00}$ mode and adjusted in polarization and peak power. We monitored energy and peak power with a boxcar averager, filtering out fluctuations greater than $10 \%$. We investigated the out-of-resonance response in the interval $980-995 \mathrm{~nm}$. The FF beam was focused to a waist of $4 \mu \mathrm{m}$ along $y \times 15 \mu \mathrm{m}$ along $x$ at the input facet of the planar PP-LT waveguide, ensuring a propagation length $>6$ Rayleigh distances. At low powers, we still observed randomly distributed $\mathrm{SH}$ with patterns along $x$ strongly dependent on both FF wavelength and input position, as previously discussed in the cw case. At high 


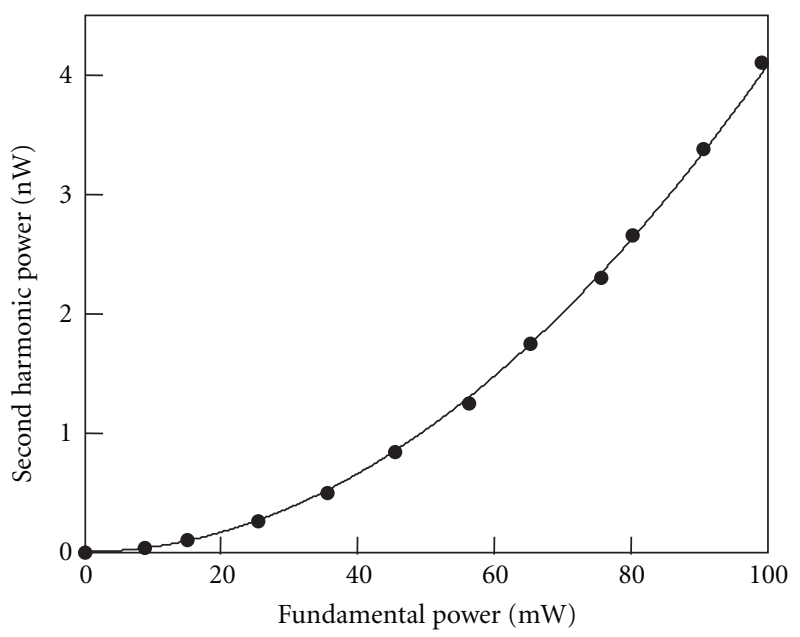

- Experiment - Square fit

(a)

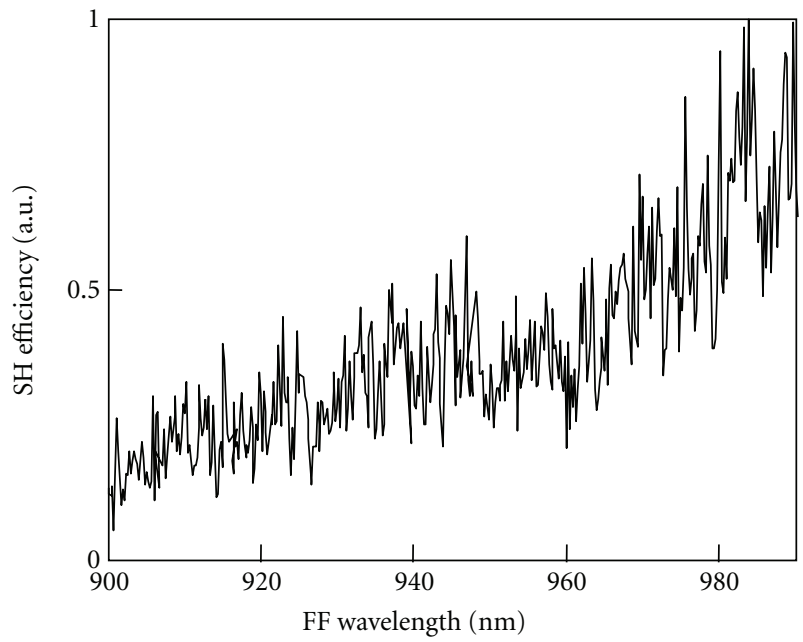

(b)

Figure 9: (a) SH generated via rQPM versus FF input power at $\lambda_{\mathrm{FF}}=929.66 \mathrm{~nm}$; (b) SHG conversion efficiency versus FF wavelength.
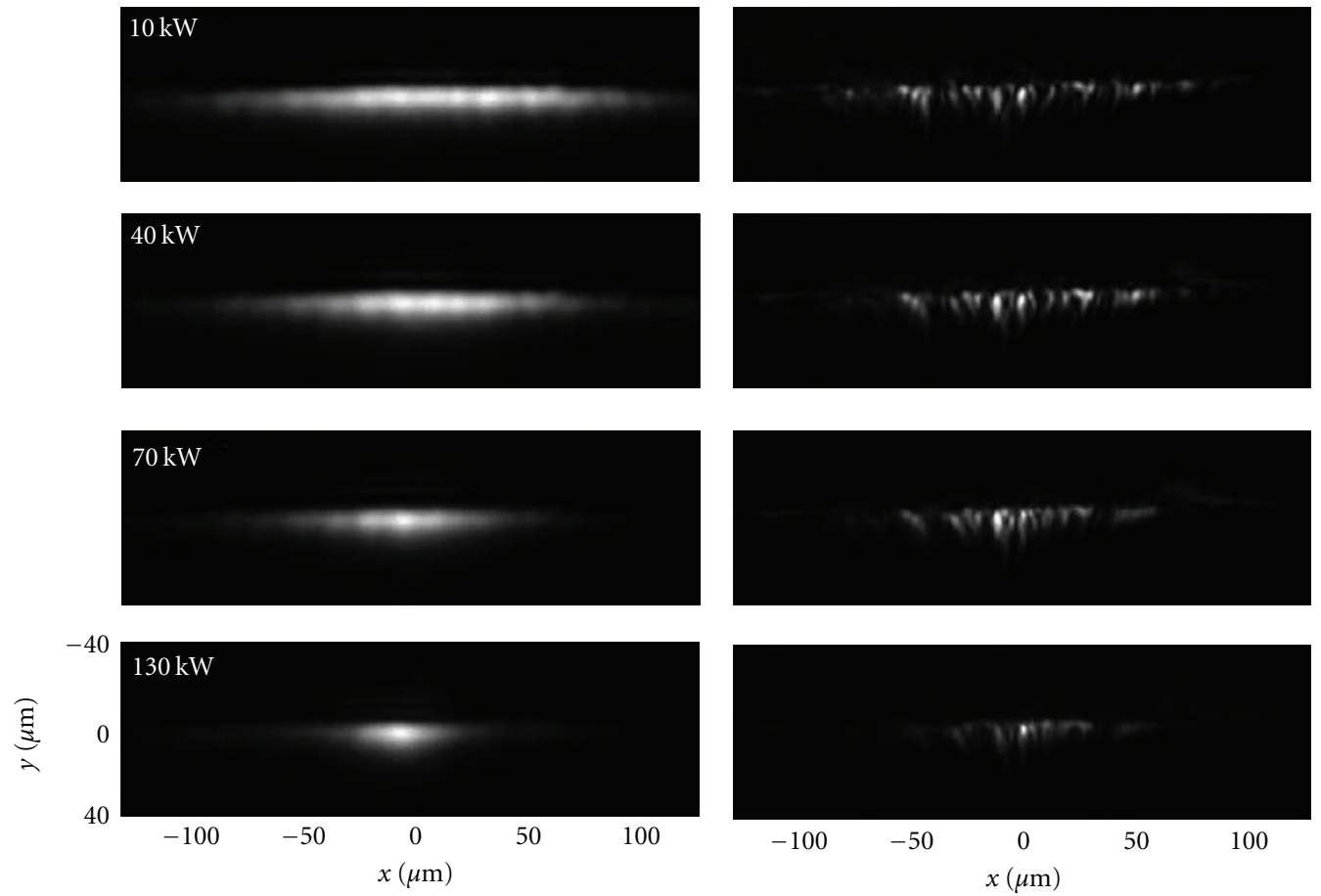

FIGURE 10: Output spots at FF (left) and SH (right) by a CCD camera for various input peak powers at $985 \mathrm{~nm}$.

excitations, quadratic solitons are expected in upconversion (i.e., with an FF input) for wavelengths longer than the resonant one, corresponding to a positive phase mismatch. At high powers, we noticed a progressive reduction in FF size at the output, with waists of about $130 \mu \mathrm{m}$ along $x$ in the quasilinear regime and of $37 \mu \mathrm{m}$ at peak excitations $>100 \mathrm{~kW}[40]$. A similar trend was detected for the envelope of the "speckled" SH signal, owing to randomness and offaxis nonlinear scattering. Figure 10 displays a selection of both FF and $\mathrm{SH}$ output beams, for various FF input peak powers. Clearly, self-focusing of both FF and SHG beams is observed for increasing FF, suggesting the formation of a two-color spatial solitary wave (simulton) in one transverse dimension. Figure 11 graphs the output FF spot size versus input peak power at both 991 and $985 \mathrm{~nm}$ : such behavior is predicted by the model detailed in [40], as well. The agreement between model and experimental results confirms that self-localization takes place via quadratic cascading [38].

The third sample we report on consists in PE channel waveguides in periodically poled congruent LT (PPLT) with 


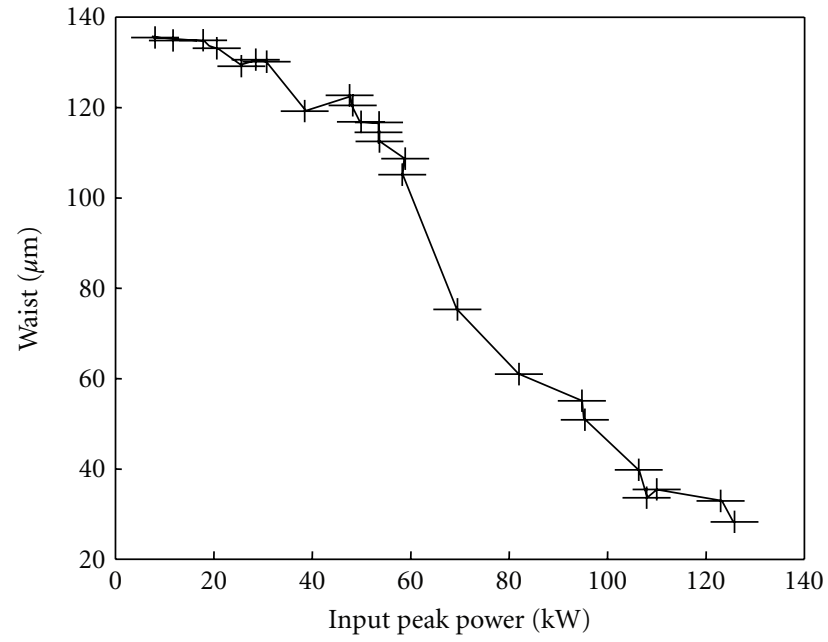

(a)

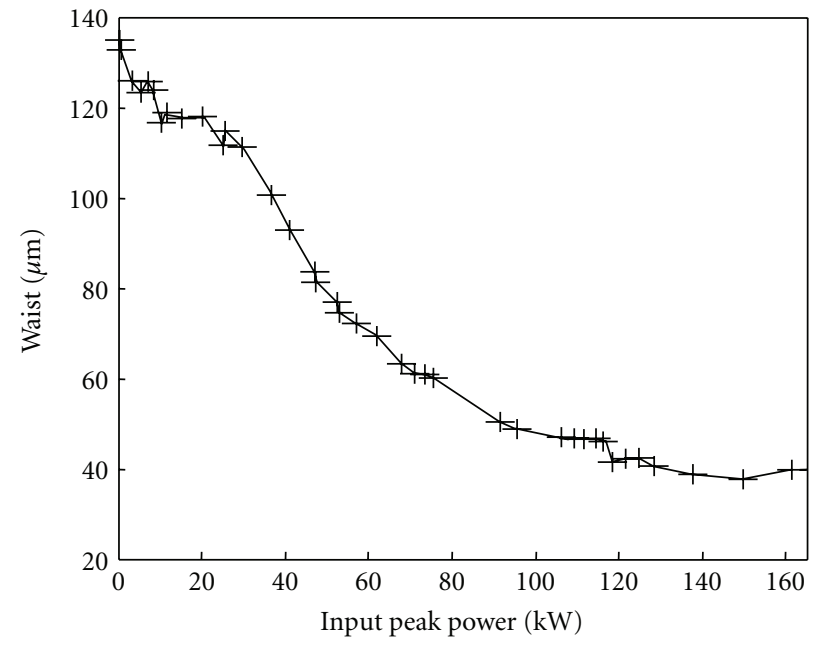

(b)

Figure 11: Measured existence curves of the FF at (a) 991 and (b) $985 \mathrm{~nm}$. Self-focusing effect and the formation of a simulton are apparent for peak powers above $100 \mathrm{~kW}$. Horizontal (vertical) error bars are statistically calculated after 100 (10) realizations.

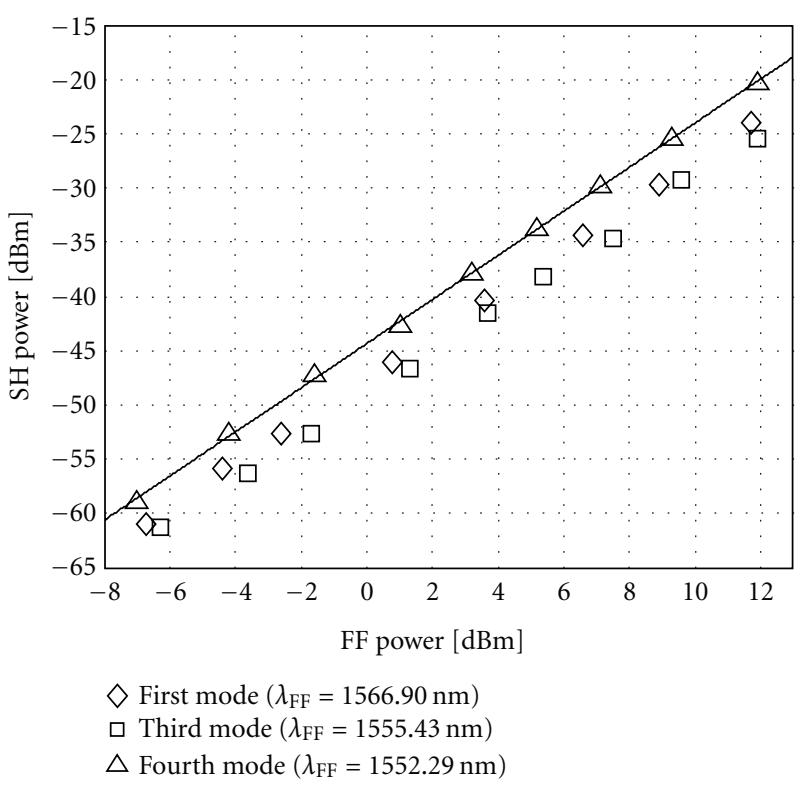

(a)

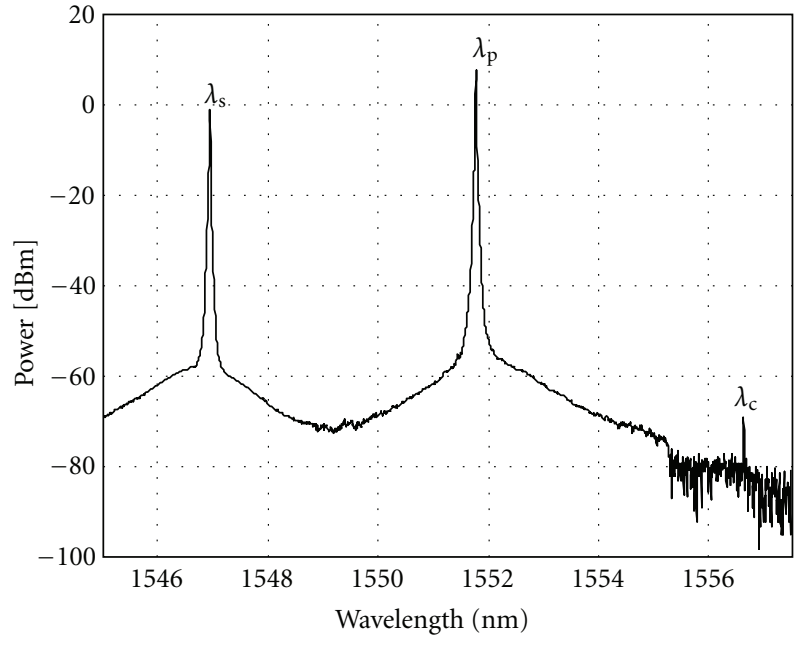

(b)

FIGURE 12: (a) SH power versus FF power at three QPM resonances in a log scale (symbols); the solid line is best fit for the most efficient SH interaction. (b) Spectral conversion in single-pass configuration.

period $20.8 \mu \mathrm{m}$ and a propagation length of $2.25 \mathrm{~cm}$. The waveguides, from 8 to $13 \mu \mathrm{m}$ wide, were fabricated as described in the previous section and resulted single mode at telecom wavelengths [61]. The nonlinear characterization was carried out at room temperature with a wavelength tunable external-cavity laser (ECL) linearly polarized and butt-coupled to the waveguides in order to excite TM modes; we used micropositioners and standard single-mode fibers with an effective area $A_{\text {eff }}=80 \mu \mathrm{m}^{2}$ and propagation losses $\alpha=0.2 \mathrm{~dB} \mathrm{~km}^{-1}$ at $1550 \mathrm{~nm}$. The output light was collected by either a microscope objective or fiber end-fire coupling, depending on the measured quantity. The overall (fiber to fiber) insertion losses in the waveguide amounted to $7 \mathrm{~dB}$. From our measurements, the coupling losses at each waveguide facet were $1.2 \mathrm{~dB}$; hence, we estimated the propagation losses in about $2 \mathrm{~dB} \mathrm{~cm}^{-1}$. Using a fundamental frequency beam in the TM polarization from the ECL, we first characterized QPM-SHG at the resonances of the FF $\mathrm{TM}_{00}$ mode with the various $\mathrm{TM}$ modes supported at the SH. By tuning the FF, we achieved quasi-phase matching at three wavelengths (Figure 12(a)): the resonance at $1566.90 \mathrm{~nm}$ corresponds to the interaction between FF 
$\mathrm{TM}_{00}$ and $\mathrm{SH} \mathrm{TM}_{00}$; those at 1555.43 and $1552.29 \mathrm{~nm}$ are due to QPM between the FF $\mathrm{TM}_{00}$ and $\mathrm{SH}$ higherorder modes. Because of the modal profiles in the graded index channel, the highest conversion efficiency was achieved between FF $\mathrm{TM}_{00}$ and the fourth SH mode (Figure 12(a)). We then tested the device as an all-optical wavelength converter (AOWC) based on quadratic cascading [66], by input coupling two copropagating continuous wave beams at distinct wavelengths in the C-band. Both inputs were amplified in erbium-doped fibre amplifiers, filtered (to rid of the out-of-band noise), and butt-coupled with a 90/10 fibre coupler. Their linear polarization was adjusted to match the $z$-axis of the PPLT. The pump beam was set at the phase matching for SHG $\left(\lambda_{p} \approx 1552.29 \mathrm{~nm}\right)$, and the probe was detuned by $\approx 5 \mathrm{~nm}\left(\lambda_{s} \approx 1547 \mathrm{~nm}\right)$. The coupled optical powers were about 100 and $15 \mathrm{~mW}$ for pump and probe, respectively. By cascading SHG and DFG, the device generated a downshifted signal $\left(\lambda_{c} \approx 1557 \mathrm{~nm}\right)$ with power larger than $100 \mathrm{nW}$ (Figure 12(b)), demonstrating for the first time both wave confinement and two-stage parametric conversion in LT channels at wavelengths around $1.5 \mu \mathrm{m}$ [45].

\section{Conclusions}

In conclusion, we summarized both the technological steps for sample fabrication by surface periodic poling and waveguide fabrication by proton exchange on ferroelectric substrates, namely, lithium tantalate and lithium niobate. The optical characterization of these micro- and nanoengineered devices, both in bulk and in guided-wave configurations, shows the high potentials of the adopted technology towards forward and backward parametric generation, down to the $\mathrm{UV}$, as well as towards cascaded wavelength shifters operating in the $\mathrm{C}$ and $\mathrm{L}$ bands. Moreover, we demonstrated that a randomized mark-to-space QPM ratio allows to obtain broadband frequency doublers with appreciable conversion efficiencies and, at higher intensities, parametric selftrapping via quadratic cascading.

\section{References}

[1] R. De Salvo, D. J. Hagan, M. Sheik-Bahae, G. Stegeman, E. W. Van Stryland, and H. Vanherzeele, "Self-focusing and selfdefocusing by cascaded secondorder effects in KTP," Optics Letters, vol. 17, pp. 28-30, 1992.

[2] G. I. Stegeman, M. Sheik-Bahae, E. Van Stryland, and G. Assanto, "Large nonlinear phase shifts in second-order nonlinear-optical processes," Optics Letters, vol. 18, no. 1, pp. 13-15, 1993.

[3] G. Assanto, G. Stegeman, M. Sheik-Bahae, and E. Van Stryland, "All-optical switching devices based on large nonlinear phase shifts from second harmonic generation," Applied Physics Letters, vol. 62, no. 12, pp. 1323-1325, 1993.

[4] G. Assanto, I. Torelli, and S. Trillo, "All-optical processing by means of vectorial interactions in second-order cascading: novel approaches," Optics Letters, vol. 19, no. 21, pp. 1720$1722,1994$.

[5] D. J. Hagan, Z. Wang, G. Stegeman, E. W. Van Stryland, M. Sheik-Bahae, and G. Assanto, "Phase-controlled transistor action by cascading of second-order nonlinearities in KTP," Optics Letters, vol. 19, no. 17, pp. 1305-1307, 1994.

[6] G. Assanto, "Transistor action through nonlinear cascading in Type II interactions," Optics Letters, vol. 20, no. 15, pp. 15951597, 1995.

[7] G. Assanto, Z. Wang, D. J. Hagan, and E. W. Vanstryland, "All-optical modulation via nonlinear cascading in type II second-harmonic generation," Applied Physics Letters, vol. 67, pp. 2120-2122, 1995.

[8] P. A. Franken, A. E. Hill, C. W. Peters, and G. Weinreich, "Generation of optical harmonics," Physical Review Letters, vol. 7, no. 4, pp. 118-119, 1961.

[9] A. Savage and R. C. Miller, "Measurements of second harmonic generation of the ruby laser line in piezoelectric crystals," Applied Optics, vol. 1, no. 5, pp. 661-664, 1962.

[10] A. Ashkin, G. D. Boyd, and J. M. Dziedzic, "Optical second harmonic generation and mixing," IEEE Journal of Quantum Electronics, vol. 2, no. 6, pp. 109-124, 1966.

[11] Y. J. Ding and J. B. Khurgin, "Second-harmonic generation based on quasi-phase matching: a novel configuration," Optics Letters, vol. 21, no. 18, pp. 1445-1447, 1996.

[12] J. A. Armstrong, N. Bloembergen, J. Ducuing, and P. S. Pershan, "Interactions between light waves in a nonlinear dielectric," Physical Review, vol. 127, no. 6, pp. 1918-1939, 1962.

[13] F. M. Pigozzo, E. Autizi, A. D. Capobianco, N. Argiolas, M. Bazzan, and C. Sada, "A novel configuration for phasematched second-harmonic generation in LiNbO3 waveguides," IEEE Photonics Technology Letters, vol. 19, no. 8, pp. 553-555, 2007.

[14] M. M. Fejer, G. A. Magel, D. H. Jundt, and R. L. Byer, "Quasi-phase-matched second harmonic generation: tuning and tolerances," IEEE Journal of Quantum Electronics, vol. 28, no. 11, pp. 3631-2654, 1992.

[15] D. Feng, N. B. Ming, J. F. Hong et al., "Enhancement of second-harmonic generation in $\mathrm{LiNbO}_{3}$ crystals with periodic laminar ferroelectric domains," Applied Physics Letters, vol. 37, no. 7, pp. 607-609, 1980.

[16] M. Houé and P. D. Townsend, “Thermal polarization reversal of lithium niobate," Applied Physics Letters, pp. 2667-2669, 1995.

[17] Yamamoto and Mizuuchi, "Blue-light generation by frequency doubling of a laser diode in a periodically domain-inverted $\mathrm{LiTaO}_{3}$ waveguide," IEEE Photonics Technology Letters, vol. 4, no. 5, pp. 435-437, 1992.

[18] S. Miyazawa, "Ferroelectric domain inversion in Ti-diffused $\mathrm{LiNbO}_{3}$ optical waveguide," Journal of Applied Physics, vol. 50, no. 7, pp. 4599-4603, 1979.

[19] C. Restoin, C. Darraud-Taupiac, J. L. Decossas, J. C. Vareille, and J. Hauden, "Ferroelectric-domain-inverted gratings by electron beam on $\mathrm{LiNbO}_{3}$," Materials Science in Semiconductor Processing, vol. 3, no. 5-6, pp. 405-407, 2000.

[20] H. Ito, C. Takyu, and H. Inaba, "Fabrication of periodic domain grating in $\mathrm{LiNbO}_{3}$ by electron beam writing for application of nonlinear optical processes," Electronics Letters, vol. 27, no. 14, pp. 1221-1222, 1991.

[21] M. Fujimura, K. Kintaka, T. Suhara, and H. Nishihara, "Blue light generation in $\mathrm{LiNbO}_{3}$ waveguide SHG device with first order domain-inverted grating formed by EB scanning," Electronics Letters, vol. 28, no. 20, pp. 1868-1869, 1992.

[22] P. W. Haycock and P. D. Townsend, "A method of poling $\mathrm{LiNbO}_{3}$ and $\mathrm{LiTaO}_{3}$ below T ," Applied Physics Letters, vol. 48, no. 11, pp. 698-700, 1986. 
[23] M. Yamada, N. Nada, M. Saitoh, and K. Watanabe, "Firstorder quasi-phase matched $\mathrm{LiNbO}_{3}$ waveguide periodically poled by applying an external field for efficient blue secondharmonic generation," Applied Physics Letters, vol. 62, no. 5, pp. 435-436, 1993.

[24] J. Webjorn, V. Pruneri, P. S. J. Russell, J. R. M. Barr, and D. C. Hanna, "Quasi-phase-matched blue light generation in bulk lithium niobate, electrically poled via periodic liquid electrodes," Electronics Letters, vol. 30, no. 11, pp. 894-895, 1994.

[25] M. Sato, P. G. R. Smith, and D. C. Hanna, "Contact electrode method for fabricating bulk periodically poled $\mathrm{LiNbO}_{3}$," Electronics Letters, vol. 34, no. 7, pp. 660-661, 1998.

[26] Y. J. Ding, S. J. Lee, and J. B. Khurgin, "Transversely pumped counterpropagating optical parametric oscillation and amplification," Physical Review Letters, vol. 75, no. 3, pp. 429-432, 1995.

[27] C. Conti, G. Assanto, and S. Trillo, "Cavityless oscillation through backward quasi-phase-matched second-harmonic generation," Optics Letters, vol. 24, no. 16, pp. 1139-1141, 1999.

[28] K. Gallo, P. Baldi, M. De Micheli, D. B. Ostrowsky, and G. Assanto, "Cascading phase shift and multivalued response in counterpropagating frequency-nondegenerate parametric amplifiers," Optics Letters, vol. 25, no. 13, pp. 966-968, 2000.

[29] A. C. Busacca, C. L. Sones, R. W. Eason, and S. Mailis, "Firstorder quasi-phase-matched blue light generation in surfacepoled Ti:indiffused lithium niobate waveguides," Applied Physics Letters, vol. 84, no. 22, pp. 4430-4432, 2004.

[30] A. C. Busacca, C. L. Sones, V. Apostolopoulos, R. W. Eason, and S. Mailis, "Surface domain engineering in congruent lithium niobate single crystals: a route to submicron periodic poling," Applied Physics Letters, vol. 81, no. 26, pp. 4946-4948, 2002.

[31] G. D. Landry and T. A. Maldonado, "Counterpropagating quasi-phase matching: a generalized analysis," Journal of the Optical Society of America B, vol. 21, no. 8, pp. 1509-1520, 2004.

[32] A. C. Busacca, A. C. Cino, S. Riva-Sanseverino, M. Ravaro, and G. Assanto, "Silica masks for improved surface poling of lithium niobate," Electronics Letters, vol. 41, no. 2, pp. 92-93, 2005.

[33] U. K. Sapaev and G. Assanto, "Femtosecond pulse synthesis by efficient second-harmonic generation in engineered quasi phase matching gratings," Optics Express, vol. 15, no. 12, pp. 7448-7457, 2007.

[34] U. K. Sapaev and G. Assanto, "Efficient high-harmonic generation in engineered quasi-phase matching gratings," Optics Express, vol. 16, no. 1, pp. 18370-18375, 2008.

[35] M. Conforti, C. De Angelis, U. K. Sapaev, and G. Assanto, "Pulse shaping via backward second harmonic generation," Optics Express, vol. 16, no. 3, pp. 2115-2121, 2008.

[36] U. K. Sapaev and G. Assanto, "Engineered quasi-phase matching for multiple parametric generation," Optics Express, vol. 17, no. 5, pp. 6765-6770, 2009.

[37] G. Assanto, "Quadratic cascading: effects and applications," in Beam Shaping and Control with Nonlinear Optics, F. Kajzar and R. Reinisch, Eds., B369, pp. 341-374, Plenum Press, New York, NY, USA, 1997.

[38] G. Assanto and G. I. Stegeman, "Simple physics of quadratic spatial solitons," Optics Express, vol. 10, no. 9, pp. 388-396, 2002.
[39] G. Leo, A. Amoroso, L. Colace, G. Assanto, R. V. Roussev, and M. M. Fejer, "Low-threshold spatial solitons in reverseproton-exchanged periodically poled lithium niobate waveguides," Optics Letters, vol. 29, no. 15, pp. 1778-1780, 2004.

[40] C. Conti, E. D’Asaro, S. Stivala, A. Busacca, and G. Assanto, "Parametric self-trapping in the presence of randomized quasi phase matching," Optics Letters, vol. 35, no. 22, pp. 3760-3762, 2010.

[41] S. Stivala, A. C. Busacca, A. Pasquazi, R. L. Oliveri, R. Morandotti, and G. Assanto, "Random quasi-phase-matched second-harmonic generation in periodically poled lithium tantalate," Optics Letters, vol. 35, no. 3, pp. 363-365, 2010.

[42] A. Pasquazi, A. Busacca, S. Stivala, R. Morandotti, and G. Assanto, "Nonlinear disorder mapping through three-wave mixing," IEEE Photonics Journal, vol. 2, no. 1, pp. 18-28, 2010.

[43] J. S. Pelc, C. R. Phillips, D. Chang, C. Langrock, and M. M. Fejer, "Efficiency pedestal in quasi-phase-matching devices with random duty-cycle errors," Optics Letters, vol. 36, no. 6, pp. 864-866, 2011.

[44] S. Stivala, F. Buccheri, L. Curcio, R. L. Oliveri, A. C. Busacca, and G. Assanto, "Features of randomized electric-field assisted domain inversion in lithium tantalate," Optics Express, vol. 19, no. 25, pp. 25780-25785, 2011.

[45] G. Nava, P. Minzioni, I. Cristiani et al., "Integrated frequency shifter in a periodically poled lithium tantalate waveguide," Electronics Letters, vol. 46, no. 25, pp. 1686-1688, 2010.

[46] S. Stivala, A. Pasquazi, L. Colace et al., "Guided-wave frequency doubling in surface periodically poled lithium niobate: competing effects," Journal of the Optical Society of America B, vol. 24, no. 7, pp. 1564-1570, 2007.

[47] M. Cherchi, S. Stivala, A. Pasquazi et al., "Second-harmonic generation in surface periodically poled lithium niobate waveguides: on the role of multiphoton absorption," Applied Physics B, vol. 93, no. 2-3, pp. 559-565, 2008.

[48] A. C. Busacca, E. D’Asaro, A. Pasquazi, S. Stivala, and G. Assanto, "Ultraviolet generation in periodically poled lithium tantalate waveguides," Applied Physics Letters, vol. 93, no. 12, Article ID 121117, 2008.

[49] J. U. Kang, Y. J. Ding, W. K. Burns, and J. S. Melinger, "Backward second-harmonic generation in periodically poled bulk $\mathrm{LiNbO}_{3}$," Optics Letters, vol. 22, no. 12, pp. 862-864, 1997.

[50] X. Gu, R. Y. Korotkov, Y. J. Ding, J. U. Kang, and J. B. Khurgin, "Backward second-harmonic generation in periodically poled lithium niobate," Journal of the Optical Society of America B, vol. 15, no. 5, pp. 1561-1566, 1998.

[51] X. Gu, M. Makarov, Y. J. Ding, J. B. Khurgin, and W. P. Risk, "Backward second-harmonic and third-harmonic generation in a periodically poled potassium titanyl phosphate waveguide," Optics Letters, vol. 24, no. 3, pp. 127-129, 1999.

[52] X. Mu, I. B. Zotova, Y. J. Ding, and W. P. Risk, "Backward second-harmonic generation in submicron-period ionexchanged $\mathrm{KTiOPO}_{4}$ waveguide," Optics Communications, vol. 181, no. 1, pp. 153-159, 2000.

[53] S. Stivala, A. C. Busacca, L. Curcio, R. L. Oliveri, S. RivaSanseverino, and G. Assanto, "Continuous-wave backward frequency doubling in periodically poled lithium niobate," Applied Physics Letters, vol. 96, no. 11, Article ID 111110, 2010.

[54] A. C. Busacca, C. A. Santini, S. Riva-Sanseverino et al., "Surface periodic poling in congruent lithium tantalate," Electronics Letters, vol. 42, no. 9, pp. 546-547, 2006.

[55] M. Bazzan, C. Sada, N. Argiolas et al., "High resolution x-ray investigation of periodically poled lithium tantalate crystals 
with short periodicity," Journal of Applied Physics, vol. 106, no. 10, Article ID 104121, 2009.

[56] A. Busacca, M. Cherchi, S. Riva Sanseverino et al., "Surface periodic poling in lithium niobate and lithium tantalate," in Proceedings of the 4th IEEE/LEOS Workshop on Fibres and Optical Passive Components (WFOPC '05), pp. 126-130, June 2005.

[57] L. Chanvillard, P. Aschiéri, P. Baldi et al., "Soft proton exchange on periodically poled $\mathrm{LiNbO}_{3}$ : a simple waveguide fabrication process for highly efficient nonlinear interactions," Applied Physics Letters, vol. 76, no. 9, pp. 1089-1091, 2000.

[58] K. El Hadi, M. Sundheimer, P. Aschieri et al., "Quasi-phasematched parametric interactions in proton-exchanged lithium niobate waveguides," Journal of the Optical Society of America B, vol. 14, no. 11, pp. 3197-3203, 1997.

[59] A. C. Busacca, E. D’Asaro, S. Riva-Sanseverino, and G. Assanto, "Stable proton exchanged waveguides in lithium tantalate," IEEE Photonics Technology Letters, vol. 20, no. 24, pp. 2126-2128, 2008.

[60] M. De Micheli, D. B. Ostrowsky, J. P. Barety et al., "Crystalline and optical quality of proton exchanged waveguides," Journal of Lightwave Technology, vol. 4, no. 7, pp. 743-745, 1985.

[61] A. C. Busacca, S. Stivala, L. Curcio et al., "Soft proton exchanged channel waveguides in congruent lithium tantalate for frequency doubling," Optics Express, vol. 18, no. 25, pp. 25967-25972, 1986.

[62] J. M. White and P. F. Heidrich, "Optical waveguide refractive index profiles determined from measurement of mode indices: a simple analysis," Applied Optics, vol. 15, no. 1, pp. 151-155, 1976.

[63] M. Marangoni, M. Lobino, R. Ramponi, E. Cianci, and V. Foglietti, "High quality buried waveguides in stoichiometric $\mathrm{LiTaO}_{3}$ for nonlinear frequency conversion," Optics Express, vol. 14, no. 1, pp. 248-253, 2006.

[64] A. C. Busacca, R. L. Oliveri, A. C. Cino, S. Riva-Sanseverino, A. Parisi, and G. Assanto, "Ultraviolet quasi-phase-matched second harmonic generation in surface periodically poled lithium niobate optical waveguides," Laser Physics, vol. 17, no. 6, pp. 884-888, 2007.

[65] M. Horowitz, A. Bekker, and B. Fischer, "Broadband secondharmonic generation in $\mathrm{Sr}_{\mathrm{x}} \mathrm{Ba}_{1-\mathrm{x}} \mathrm{Nb}_{2} \mathrm{O}_{6}$ by spread spectrum phase matching with controllable domain gratings," Applied Physics Letters, vol. 62, no. 21, 1993.

[66] K. Gallo, G. Assanto, and G. I. Stegeman, "Efficient wavelength shifting over the erbium amplifier bandwidth via cascaded second order processes in lithium niobate waveguides," Applied Physics Letters, vol. 71, no. 8, pp. 1020-1022, 1997. 

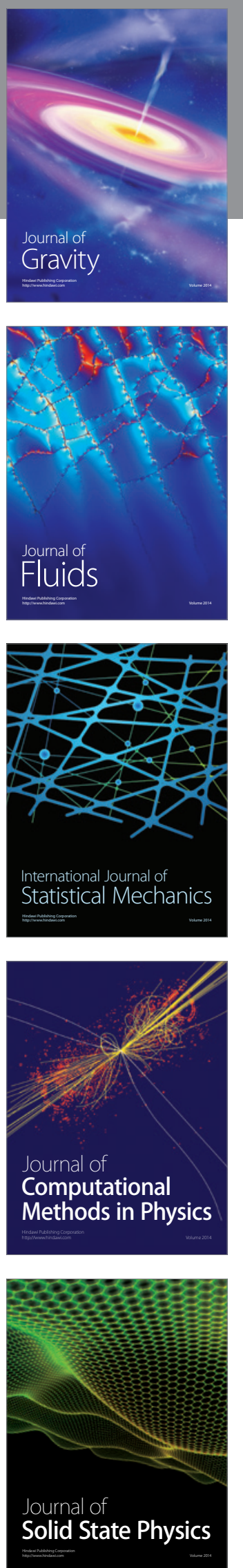

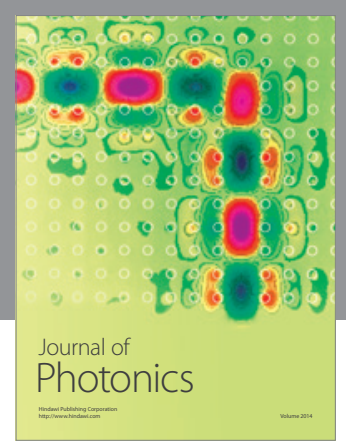

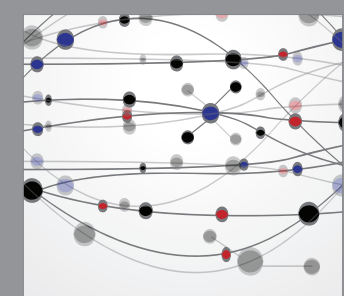

The Scientific World Journal
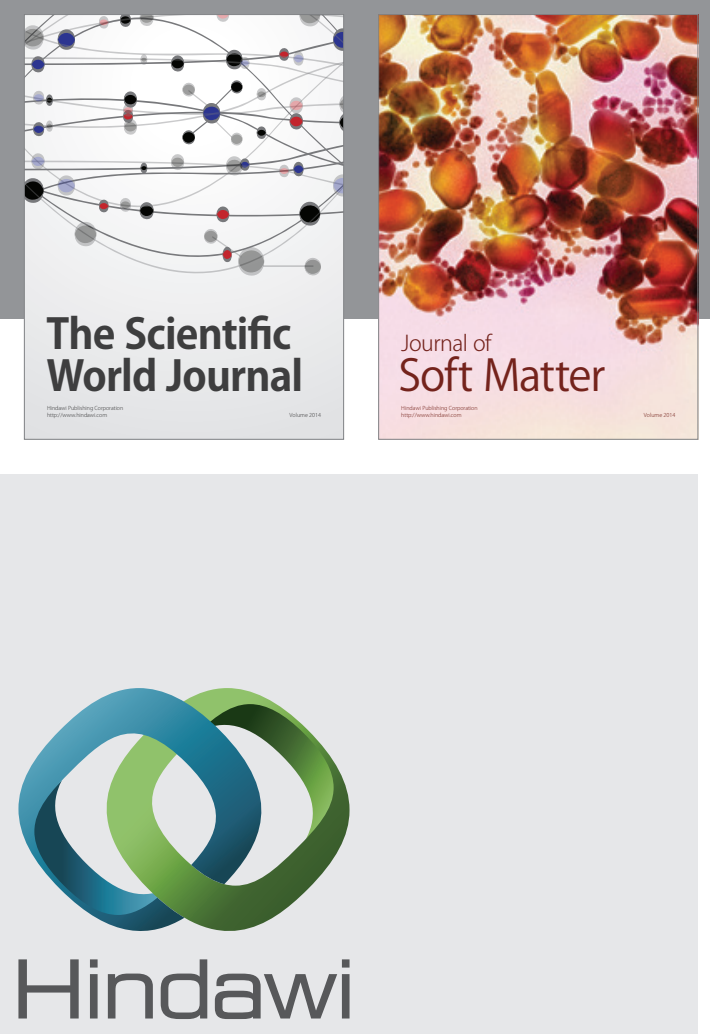

Submit your manuscripts at

http://www.hindawi.com
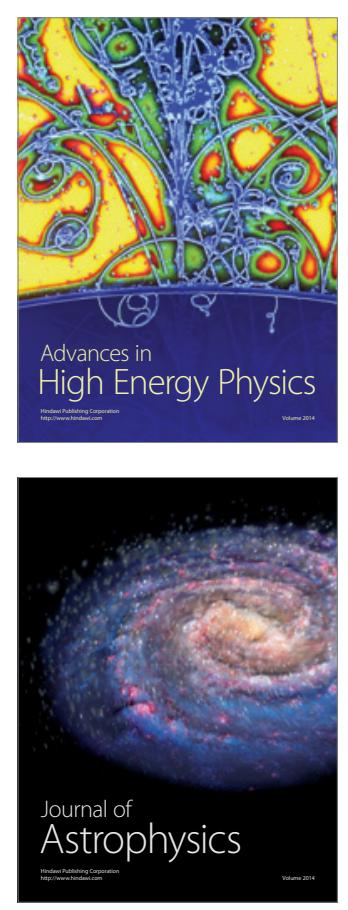
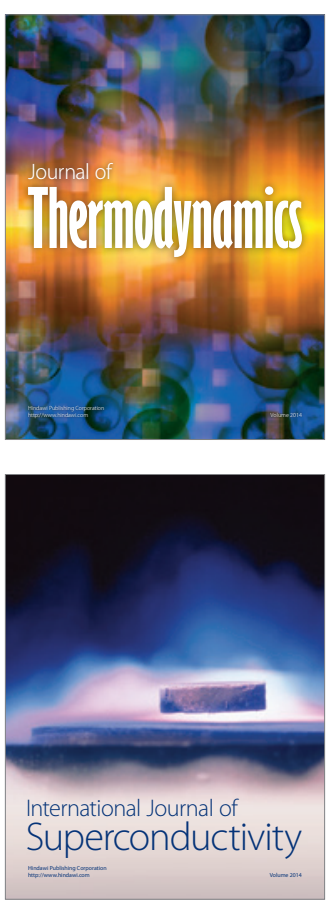
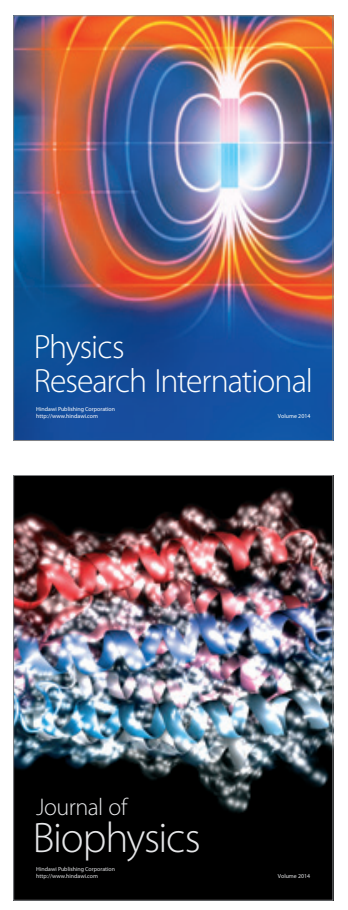
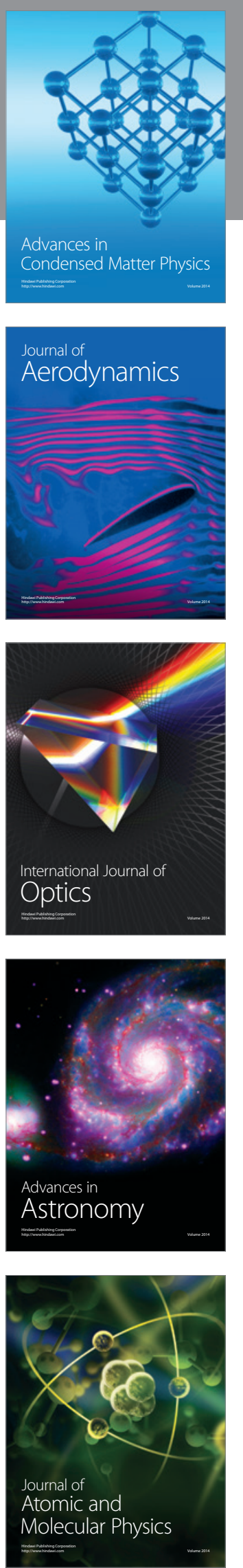